\title{
Phonological recoding: Is the regularity effect consistent?
}

\author{
SALLY ANDREWS \\ University of New South Wales, Kensington, New South Wales 2033, Australia
}

\begin{abstract}
An attempt was made to distinguish between the dual-access and the activation and synthesis models of word identification. Word regularity and consistency were factorially manipulated. In two experiments lexical decisions were required, and in two the task was word naming. Within each task, comparisons were made of the effects achieved by manipulating the degree to which subjects were free to rely on a phonological, rather than a visual, stimulus code. The results suggested that lexical access generally involves the activation of lexical entries that are visually similar to the target, but that subjects do favor a phonological code when the task requires the naming of words only. The data were interpreted as requiring a model incorporating elements of both the dual-access and the activation and synthesis frameworks.
\end{abstract}

The century-old debate as to whether visual word recognition relies on a visual or a phonological analysis has been resolved to the extent that most researchers now support some version of the dual-access model (Figure 1): Lexical access is attempted in parallel on the basis of visual and phonological codes, and the response is determined by the route that first reaches completion. The obvious distinction between the two routes is that the use of a phonological access code requires that the reader be able to apply rules that convert a string of graphemes into a phonological representation. Coltheart (1978) argued that the only viable set of such rules is the set of grapheme-phoneme correspondence (GPC) rules that is defined by the fact that the unit of analysis is essentially the individual grapheme. Whether or not this argument is valid, the necessary outcome of the juxtaposition of any hard-and-fast set of conversion rules with the irregularity of the English language is that the rules will not be successful in generating the correct pronunciation for all words. That is, if phonological conversion is ever being used, there will be differences in performance between words that are regular and words that are exceptional with respect to the rules. In the terms of the dual-access model, this is because exception words will only be able to be accessed by the visual route and will therefore, on average, be more slowly responded to than regular words, which can achieve access via either route.

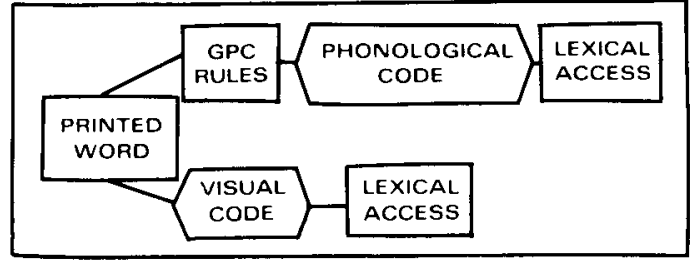

Figure 1. Schematic representation of dual-access model.
Within the lexical decision task, the "pseudohomophone effect" provides a further index of phonological conversion. This refers to the relatively robust finding (Meyer, Schvaneveldt, \& Ruddy, 1974; Rubenstein, Lewis, \& Rubenstein, 1971) that nonword classification takes longer when the nonword sounds identical to a word (e.g., BURD) than when it does not (e.g., DURD). Such an effect could only arise if lexical access was attempted on the basis of a phonological representation and was therefore delayed by an apparent match with the word BIRD.

Conclusions about the role of phonological conversion based on these two phenomena are somewhat equivocal. Effects of regularity are usually evident in the word-naming task (e.g., Baron \& Strawson, 1976; Gough \& Cosky, 1977), but it cannot be assumed that such effects occur prior to lexical access. It may be either that there exists a route directly from rules to pronunciation that bypasses the lexicon and that could be used for regular, but not irregular, words (Coltheart, Besner, Jonasson, \& Davelaar, 1979), or that regularity effects in the naming task are due to processes subsequent to lexical access concerned with generating an articulatory program for the pronunciation.

The lexical decision task provides a more stringent test of the role of prelexical phonological conversion because the task necessitates lexical access and does not require that the word be pronounced. The results obtained with this paradigm are conflicting: The pseudohomophone effect is taken as evidence of phonological recoding of nonword stimuli, but phonological effects, such as regularity, are rarely evident for words (e.g., Coltheart et al., 1979; Mason, 1978). On the basis of a review of a wide range of evidence of this type, Coltheart (1978) concluded that although parallel phonological access is attempted in the lexical decision task, the phonological route is so slow that it generally only plays 
a role when the visual route is unsuccessful, as is the case with nonwords.

\section{Regularity vs. Consistency}

Glushko (1979) presented a model that reinterpreted the regularity effects obtained in the word naming task in such a way as to suggest that the phonological route of the dual-access model does not exist. The major justification for believing in a memorial representation of GPC rules is the ability to pronounce nonwords for which there is no lexical entry (Coltheart, 1980). Glushko presented evidence that nonwords are, at least sometimes, pronounced via an analogy mechanism, such as that proposed by Baron (1977). This led Glushko to his "activation and synthesis" model, in which the pronunciation of both words and nonwords is achieved via the same mechanism: "As letter strings are identified there is parallel activation of phonological and orthographic knowledge from ... . words that share features with the letter string. A pronunciation is generated using procedures for determining how to modify the activated information in order to synthesize the desired articulatory program" (p. 678).

Within this context, word identification will not be affected by whether the word is regular or exceptional in terms of linguistically defined rules. Rather, in the course of their identification, words (or nonwords) will activate information that is either consistent or inconsistent, and inconsistent activated information will make the synthesis of a pronunciation more difficult. Glushko (1979) evaluated his model by comparing three types of stimuli: (1) words that were both regular by the rulebased definition and consistent by his new definition (e.g., WADE, HAZE); (2) words that were regular, but inconsistent, in that other words with the same orthographic pattern are pronounced differently (e.g., SAVE); and (3) exception words (e.g., HAVE). In accordance with Glushko's predictions, the inconsistent words resulted in longer naming latencies, regardless of regularity, and he concluded that "this penalty for words that have exceptional neighbors suggests that the historical definition for regular and exception words may be inappropriate for psychological models of reading" (p. 686).

\section{Dual Access vs. Activation and Synthesis}

Glushko (1979) is proposing that the previously obtained regularity effects are the result of the confounding of regularity and consistency and that, therefore, the presumed "phonological effects" are not the result of rules applied either prelexically or postlexically, but rather arise within the lexicon because of the activation of inconsistent information from visually similar words. In the terms of the dual-access model, Glushko argues that there is only one route: the visual one.

Glushko's (1979) argument hinges on his finding that when regular/consistent, regular/inconsistent, and excep- tion words are compared, there are effects of consistency but not regularity. It is, however, impossible to draw this conclusion from Glushko's data. His exception words were, by the joint definition, irregular and inconsistent. He did not include the fourth condition (irregular but consistent words) because, he argued, such words tend to be unusual words like SCHISM that "make poor stimuli" (p.684). However, without this fourth cell of the factorial design, it is impossible to evaluate whether there are effects of only consistency, as Glushko claims, or whether there are effects of both regularity and consistency. In fact, an examination of Glushko's data suggests that regularity effects are operative. Although the latencies for regular/inconsistent (e.g., SAVE) and exception (e.g., HAVE) words are essentially identical, the exception condition words are of higher frequency than the other two conditions, suggesting that if frequency had been equated, there may have been a difference between regular and irregular inconsistent words. More important, there is a large difference in the error rates between the two inconsistent conditions $(2.9 \%$ vs. $8.3 \%$ ), for which Glushko fails to report significance tests. The same type of criticisms apply to Bauer and Stanovich's (1980) replication of Glushko's experiment, in which there is a suggestion of a speed-accuracy tradeoff between the regular/inconsistent and exception conditions.

In that Glushko's support for the activation and synthesis over the dual-access model relies on the absence of a regularity effect, an investigation of the fully factorial combination of regularity and consistency is essential.

\section{The Experimental Manipulations}

Within subjects. The first aim of the experiments was to investigate the fully factorial combination of regularity and consistency. Regularity was defined as conformity to GPC rules, such as those of Venezky (1970). Consistency was defined as meaning that all other words that differ from the stimulus in only the initial consonant or consonant cluster, and are of approximately the same length as the stimulus, are pronounced in the same way. Words were selected that were, in terms of this joint definition, regular/consistent, regular/inconsistent, irregular/consistent, and irregular/ inconsistent. In order to ensure that the four groups of words were as equivalent as possible on all other dimensions, all stimuli were sampled from the population of four-letter words of the form CVCC or CVVC.

It has been suggested that the choice of route within the dual-access framework may be a function of word frequency (McCusker, Hillenger, \& Bias, 1981), so half the words of each type were of high and low frequency in the language. Examples of stimuli of each type are presented in Figure 2. (The full stimulus list is in the appendix.)

Between subjects. The between-subjects manipulations were designed to distinguish the dual-access and 


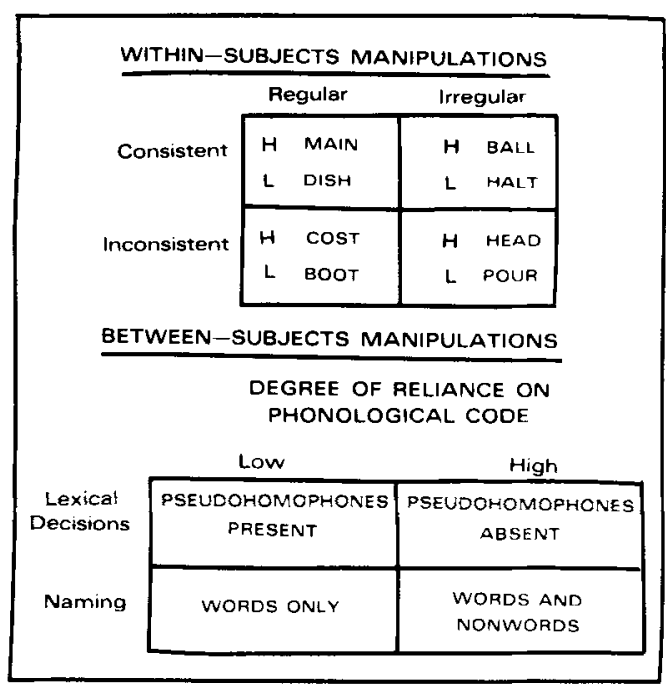

Figure 2. Design of experiments, including examples of the eight stimulus types used in the within-subjects manipulations (H = high frequency; $L=$ low frequency).

activation and synthesis models. In general, the activation and synthesis model predicts that there will be effects of consistency, but not of regularity, whereas the dual-access model predicts regularity effects, but cannot accommodate any effects of consistency.

Naming vs. lexical decision tasks. As originally stated, Glushko's (1979) model proposed that consistency effects arise because of the difficulty of synthesizing a pronunciation from inconsistent activated information. He would therefore predict that consistency effects would be evident in the word-naming task, but he would have no reason to expect effects of consistency in the lexical decision task because pronunciation is not required.

The dual-access model predicts that regularity effects arise whenever the phonological route completes before the visual route. It has been suggested that this is rarely the case in the lexical decision task, but may be more likely in the naming task (Coltheart, 1978).

Manipulation of the degree of reliance on a phonological code. A further attempt to distinguish the two models involved manipulating the degree to which subjects could rely on a phonological vs. a visual stimulus code. Within the dual-access model, it is possible to conceive of the two routes being differentially weighted in accordance with task demands (Share, Note 1). A bias toward the phonological route would result in enhanced regularity effects relative to conditions in which the visual route is favored.

In the naming task, an attempt to manipulate these weightings was made by comparing a condition in which subjects had to name both words and nonwords with a condition in which only words were presented. The dualaccess view assumes that nonword pronunciation can only be achieved via the GPC route. Thus, the inclusion of nonwords may result in a bias toward the phonologi- cal strategy and, therefore, enhanced regularity effects relative to the condition in which only words must be named and subjects are, in principle, free to rely on the visual access strategy. If the phonological route is slower than the visual (e.g., Coltheart, 1978; Marshall, 1976), this view would also predict slower latencies in the condition involving pronunciation of both words and nonwords.

A similar manipulation was attempted in the lexical decision task by comparing a condition in which half the nonword stimuli were pseudohomophones with a condition in which no pseudohomophones were included. Davelaar, Coltheart, Besner, and Jonasson (1978) found that the inclusion of pseudohomophonic nonword stimuli resulted in decreased phonological effects, presumably because of subjects' realization that reliance on a phonological code caused them to make errors on pseudohomophonic nonwords. In the present terms, the decreased phonological effects result from a bias toward the visual, rather than the phonological, route. This interpretation is similar in essence, if not in detail, to that of Davelaar et al. If this change in bias does occur, it would be expected that any regularity effects observed in the lexical decision task would be attenuated when pseudohomophones are present rather than absent, because when no pseudohomophones are presented, the subjects are free to rely on the phonological route if they wish.

The activation and synthesis model, on the other hand, would predict no effect of either of these manipulations. There is no phonological route, so there is no mechanism by which phonological effects can appear and disappear according to task demands. Within the naming task, to which Glushko (1979) has specifically addressed himself, he proposes that "words and pseudowords are pronounced using similar kinds of orthographic and phonological knowledge" (p. 674), and there is therefore no reason why requiring subjects to pronounce pseudowords as well should influence the naming latency for words.

\section{EXPERIMENTS 1A AND 1B: LEXICAL DECISION TASKS}

\section{Method}

Subjects. The subjects for both experiments were undergraduates who received course credit for participation. Twentytwo subjects were tested in Experiment 1A, and 20 others were tested in Experiment $1 \mathrm{~B}$.

Stimuli for Experiment lA (pseudohomophones present). Eighty four-letter words of the form CVVC or CVCC were selected such that they conformed to the factorial combination of regularity and consistency. Of the the 20 words allocated to each regularity by consistency combination, 10 were high frequency (greater than 40, according to Kucera \& Francis, 1967), and 10 were low frequency (frequencies of less than 20). The frequencies were matched as closely as possible across the high and low conditions.

There were 80 nonword stimuli constructed. Forty of these were pseudohomophones that, when pronounced, sounded 
identical to a word. The other 40 nonwords were orthographically and phonologically legal, but were not pronounced in the same way as a word. All nonwords were four letters long.

Stimuli for Experiment 1B (pseudohomophones absent). These were identical to those used in Experiment 1A, except that the pseudohomophonic nonwords were not included.

Procedure. Subjects were informed that stimuli would be presented on a video screen and that they should, as quickly and accurately as possible, press one key with their dominant hand if the stimulus was a word and another key if it was a nonword. Words and nonwords were randomly ordered, and all stimuli were presented in uppercase. Stimuli were presented for $3 \mathrm{sec}$, and there was a constant interstimulus interval of $4.5 \mathrm{sec}$. A minicomputer controlled stimulus presentation and response collection. Twenty practice trials were administered to accustom subjects to the task demands and procedure.

\section{Results}

For all results reported, spuriously long or short reaction times were trimmed to a criterion of 3 standard deviations from the mean for that subject and condition. Two analyses were conducted, one treating subjects as a random factor and one treating items as a random factor. The corresponding $F$ ratios will be reported as $F_{s}$ and $F_{i}$, respectively. Only the analyses of word stimuli will be reported.

The mean latencies for the eight conditions, averaged over all subjects who made less than $15 \%$ errors, are presented in Figure 3.

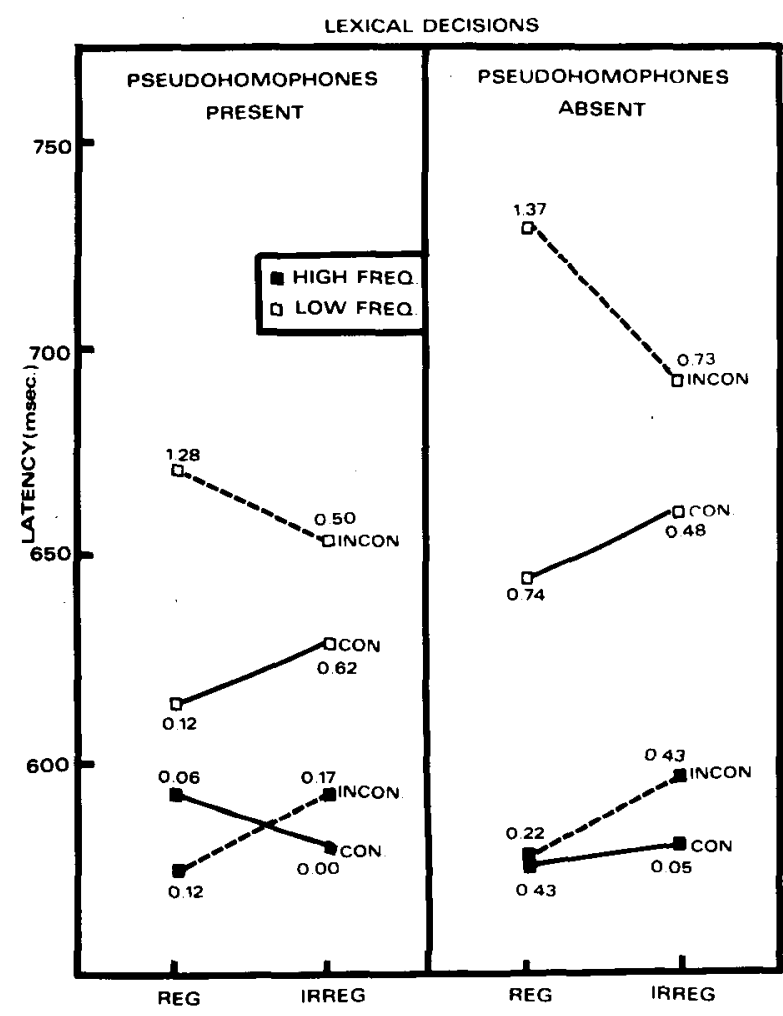

Figure 3. Mean lexical decision times and mean error rates as a function of regularity, consistency, and word frequency for Experiments $1 \mathrm{~A}$ and $1 B$.
Experiment 1A. When pseudohomophones were present, there was a reliable effect of frequency $\left[F_{s}(1,18)=68.3 ; F_{i}(1,72)=15.9\right]$, and the interaction between frequency and consistency was significant by subjects but not by items $\left[F_{s}(1,18)=16.6\right.$; $\left.F_{i}(1,72)=3.1\right]$. This interaction reflected the fact that consistency affected latencies for low $\left[F_{s}(1,18)=22.4\right.$; $\left.F_{i}(1,72)=5.2\right]$ but not high $\left(F_{s}\right.$ and $\left.F_{i}<1\right)$ frequency words. The significant consistency effect for low frequency words resulted from the fact that inconsistent words were classified more slowly than consistent words. There were no main effects or interactions resulting from the manipulation of regularity (all $F_{s} s$ and $F_{i} s<1$ ). The analysis of errors showed a significant effect of frequency $\left[F_{s}(1,18)=14.8 ; F_{i}(1,72)=6.2\right]$. Although the subjects analysis revealed significant effects of consistency $\left[F_{s}(1,18)=6.7\right]$, consistency by frequency $\left[\mathrm{F}_{\mathrm{S}}(1,18)=4.3\right]$, and consistency by regularity by frequency $\left[F_{s}(1,18)=6.8\right]$, none of these were reliable when items were treated as a random factor ( $a l l F_{i} s<1.4$ ).

Experiment 1B. The analysis of the mean latencies obtained when pseudohomophones were absent was essentially identical to that of Experiment 1A. Frequency had a significant effect $\left[\mathrm{F}_{\mathrm{s}}(1,17)=77.5\right.$; $\left.\mathrm{F}_{\mathrm{i}}(1,72)=27.4\right]$, as did consistency for low frequency words $\left[F_{s}(1,17)=22.8 ; F_{i}(1,72)=4.4\right]$. The average effect of consistency and the Frequency by Consistency interaction were significant over subjects but not items $\left[F_{s}(1,17)=17.7, F_{i}(1,72)=2.9\right.$ and $F_{s}(1,17)=14.1$, $F_{i}(1,72)=1.6$, respectively]. There were no reliable effects of regularity. The error analysis revealed reliable effects of frequency $\left[F_{s}(1,17)=47.1 ; F_{i}(1,72)=5.9\right]$ and an interaction between regularity and consistency for the low frequency words $\left[F_{s}(1,17)=19.5\right.$; $\left.F_{i}(1,72)=4.1\right]$. Once again, the subjects analysis showed significant effects of consistency $\left[F_{s}(1,17)=\right.$ $8.9]$, consistency by frequency $\left[\mathrm{F}_{\mathrm{s}}(1,17)=7.8\right]$, and consistency by frequency by regularity $\left[F_{s}(1,17)=25.9\right]$, but only the three-way interaction approached significance in the items analysis $\left[\mathrm{F}_{\mathrm{i}}(1,72)=2.9\right]$.

Experiment 1A vs. Experiment 1B. There was a difference in overall latency between the two tasks that was significant by items but not subjects $\left[\mathrm{F}_{\mathrm{s}}(1,36)=.34\right.$ $\left.F_{i}(1,72)=5.5\right]$, as well as a Task by Frequency interaction $\left[F_{s}(1,36)=9.9 ; F_{i}(1,72)=5.5\right]$. This reflected the fact that when pseudohomophones were absent, the latencies to low frequency words were much longer than when pseudohomophones were present. There was a significant difference in the overall error rates in the two experiments $\left[F_{s}(1,36)=4.1 ; \quad F_{i}(1,72)=15.2\right]$. This difference paralleled the differences in latency: Subjects were more accurate when pseudohomophones were present than when they were absent.

\section{Discussion}

In that there were effects of consistency and essentially no effects of regularity, the data seem to support 
Glushko's (1979) activation and synthesis model. However, the implication of Glushko's discussion of his model was that consistency effects arise in the course of synthesizing a pronunciation. In order to account for the fact that such effects occur in the lexical decision task in which a pronunciation is not required, it would be necessary to assume that inconsistent information causes general problems in deciding which particular lexical entry matches the stimulus, as opposed to specific problems in generating a pronunciation. There is evidence from other sources, such as rhyming and Stroop tasks, that multiple codes for a single stimulus are activated during word processing (e.g., Seidenberg $\&$ Tannenhaus, 1979; Tannenhaus, Flanigan, \& Seidenberg, 1980). If it is assumed that more than one lexical entry achieves criterion and that, therefore, a decision as to which stimulus was presented requires a search through all of these activated entries (e.g., Becker, 1976), then it seems plausible that heterogeneity of the information obtained from the multiple codes available for inconsistent words would result in delayed classification. The finding that consistency effects only occurred for low frequency words is compatible with the model, although not predicted by Glushko. In that inconsistent information is derived from lexical entries that are activated in the course of stimulus identification, the low thresholds presumed the be associated with high frequency words (e.g., Morton, 1969) would result in there being less opportunity for potentially inconsistent neighbors to have achieved threshold during stimulus processing than would be the case for low frequency words for which the threshold is high.

The fact that there were differences between the pseudohomophones-present and -absent conditions, however, is not in accord with Glushko's (1979) model. But neither is the difference between the experiments consistent with the dual-access model. It seems that the inclusion of pseudohomophonic stimuli makes the task easier, as reflected by both faster latencies and fewer errors. This result is counterintuitive: Pseudohomophones are obviously more similar to words than equivalently legal nonwords that do not sound like words; therefore, it would be expected that their inclusion would make the task more difficult, in the same way that the inclusion of pronounceable rather than unpronounceable nonword stimuli makes lexical classification harder (Shulman, Hornak, \& Sanders, 1978).

It is difficult to interpret the differences between the two experiments in any terms other than a differential reliance on phonological information. It was predicted, on the basis of Davelaar et al.'s (1978) results, that the inclusion of pseudohomophones would induce subjects to decrease their reliance on the phonological route if such a route existed. The nonword data for Experiment $1 \mathrm{~A}$ support this prediction: There was no difference between the mean classification latency for pseudohomophones (780 msec) and legal nonwords $(787 \mathrm{msec})$. This con- trasts with the usual finding (e.g., Rubenstein et al., 1971) of slower classification of pseudohomophones. But the fact that pseudohomophones were not classified more quickly than legal nonwords argues against the possibility that the pseudohomophones make the task of lexical classification easier because they are not as visually similar to words as the other legal nonwords. It seems, then, that the presence of pseudohomophones and a large number of exception words caused subjects to attempt to avoid the influence of phonological information.

Coltheart, Davelaar, Jonasson, and Besner (1977) proposed a mechanism that could be modified to accommodate faster word classification in situations in which phonological information is likely to be misleading. As a solution to the problem that the logogen system cannot say "no," Coltheart et al. (1977) proposed that a deadline be set such that "if no logogen has reached threshold by $t$ msec after stimulus onset, decide that none is going to, and respond "no"' (p. 546). They produced evidence suggesting that this deadline value is adjusted according to the overall level of excitation in the logogen system. As it stands, this mechanism cannot explain the obtained effects because the deadline is responsive only to the amount of activity in the system, and it is presumed to affect only "no" responses. If, however, it is assumed that the deadline can be "deliberately" lowered in the presence of pseudohomophones in order to avoid the possibility that the phonological route will complete in time to influence the response, and if it is further assumed that when the "no" deadline is lowered, the thresholds for all word detectors are also lowered so that they can fire before the deadline elapses, then this modified deadline notion would predict faster classifications in Experiment 1A than in Experiment 1B. This was the effect observed for low frequency words. The lack of a similar facilitation for high frequency words could easily be a "floor effect." A similar decrease in word classification time under conditions favoring visual rather than phonological analysis was observed by McQuade (1981).

There is, however, a problem with this deadline explanation: Any decrease in word thresholds should be accompanied by an increase in errors. Quite the opposite was the case. Subjects were not only faster in Experiments $1 \mathrm{~A}$ and $1 \mathrm{~B}$, but they were also more accurate.

\section{EXPERIMENTS 2A AND 2B: NAMING TASKS}

The lexical decision data are equivocal. They support Glushko's (1979) model because there are effects of consistency but not regularity and because this overall pattern of results is identical whether pseudohomophones are present or absent. On the other hand, the improvement in performance resulting from the inclusion of pseudohomophones is difficult to interpret without assuming that there is decreased reliance on phonological 
information and, therefore, that the second route of the dual-access model does exist. However, the reduced deadline that the dual-access model would need to assume to account for this effect would predict a speedaccuracy tradeoff that is not evident.

If we ignore this problem and assume that the differences between Experiments $1 \mathrm{~A}$ and $1 \mathrm{~B}$ do reflect differential reliance on phonological information, the question that remains for the dual-access view is why there are no effects of regularity in Experiment 1B, in which phonological information is allowed to play a role. The popular dual-access explanation (Coltheart, 1978; Marshall, 1976 ) is that the phonological access route is so much slower than the visual route that it only influences nonword classifications. If this is the case, then regularity effects should be more evident in the word-naming task because the requirement of producing a pronunciation is likely to result in a bias toward the phonological route.

\section{Method}

Subjects and Stimuli. Forty-three new subjects from the same undergraduate population were tested. The stimulus materials were identical to those of Experiment $1 \mathrm{~A}$, but 20 subjects were presented with only the 80 word stimuli (Experiment $2 \mathrm{~A}$ ), whereas 23 received both words and nonwords (Experiment 2B).

Procedure. Presentation of stimuli was identical to that in Experiments $1 \mathrm{~A}$ and $1 \mathrm{~B}$, but subjects were instructed to read the stimulus into a microphone and to begin their vocalizations as quickly as possible. Four latencies were collected for each subject for each stimulus. These four latencies corresponded to the time between stimulus presentation and the closing of a circuit, for which the volume level required to close the circuit was set at four different levels. Twenty practice trials were presented, during which time the volume levels were adjusted for each individual subject. Subjects' responses were taped for error analysis. ${ }^{1}$

\section{Results}

The four latencies collected for each word were averaged, after removing spuriously short or long latencies presumed to result from low level noise that closed low volume circuits or soft responses that did not close high volume circuits. The remaining latencies were averaged unless they were more than $20 \mathrm{msec}$ apart, in which case the data for that trial were discarded; if this was necessary for more than $5 \%$ of a subject's trials, that subject was discarded. Two such subjects were discarded from Experiment $2 \mathrm{~A}$ and one from Experiment 2B. The mean latencies thus obtained, averaged over subjects, are presented in Figure 4.

Experiment 2A: Naming words only. The main effect for frequency was reliable for both subjects and items $\left[F_{s}(1,17)=15.1 ; F_{i}(1,72)=5.5\right]$, as was the main effect for consistency $\left[F_{s}(1,17)=26.6 ; F_{i}(1,72)=8.6\right]$. There was no Frequency by Consistency interaction $\left(F_{s}\right.$ and $\left.F_{i}<1\right)$. The interaction between frequency and regularity was significant by subjects but not by items $\left[F_{s}(1,17)=\right.$ $\left.11.5 ; F_{i}(1,72)=2.8\right]$. This interaction resulted from the fact that for low frequency words, irregularity caused an

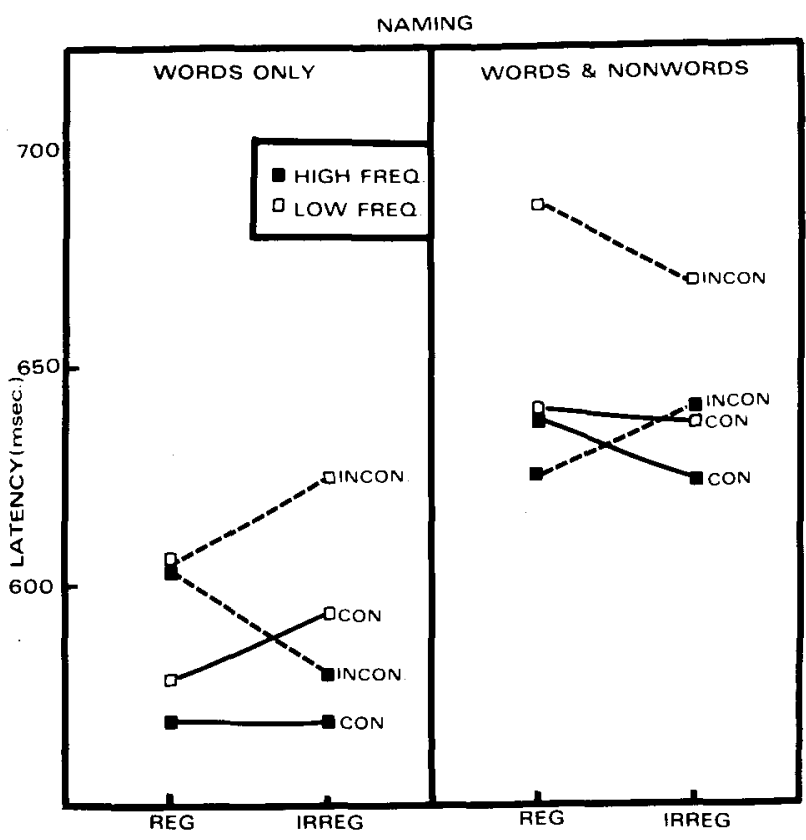

Figure 4. Mean word-naming times as a function of regularity, consistency, and word frequency for Experiments $2 \mathrm{~A}$ and $2 \mathrm{~B}$.

increase in latency, whereas there was a slight tendency in the opposite direction for high frequency words.

Experiment 2B: Naming words plus nonwords. There was once again a reliable frequency effect $\left[F_{s}(1,21)=8.3\right.$; $\left.F_{i}(1,72)=6.9\right]$. There was a reliable consistency effect $\left[\mathrm{F}_{\mathrm{s}}(1,21)=6.9 ; \mathrm{F}_{\mathrm{i}}(1,72)=4.9\right]$ and a Consistency by Frequency interaction $\left[\mathrm{F}_{\mathrm{s}}(1,21)=8.1\right]$ that did not quite reach significance when items were treated as a random factor $\left[F_{i}(1,72)=3.5\right]$. As in the lexical decision tasks, this interaction resulted from the fact that consistency affected latencies for low $\left[\mathrm{F}_{\mathrm{s}}(1,21)=12.5\right.$; $\left.F_{i}(1,72)=8.3\right]$ but not high $\left(F_{s}\right.$ and $\left.F_{i}<1\right)$ frequency words.

Experiment 2A vs. Experiment 2B. There was an overall difference in latency between the two experiments $\left[F_{s}(1,39)=4.3 ; F_{i}(1,72)=5.5\right]$, obviously because word latencies were slower when subjects were also required to name nonwords than when they were presented only with words. The Task by Frequency interaction was significant by items but not subjects $\left[\mathrm{F}_{\mathrm{s}}(1,39)=.28 ; \mathrm{F}_{\mathrm{i}}(1,72)=6.9\right]$. There was a Task by Frequency by Regularity interaction $\left[F_{s}(1,39)=6.2\right.$; $\left.F_{i}(1,72)=4.3\right]$ because regularity effects were evident for low frequency words when only words had to be named, but there were no regularity effects in the wordsplus-nonwords condition.

\section{Discussion}

As in the lexical decision tasks, the existence of consistency effects supports Glushko's (1979) model, but the task interactions and the presence of a regularity effect for low frequency words in the naming-words- 
only task support the dual-access model. If there is no phonological route, as Glushko suggests, then there should be no effects of regularity; and if words and nonwords are named via the same mechanism, then word latency should not be affected by requiring that nonwords be named as well.

However, the nature of the task interactions obtained are not quite in accord with the dual-access model. This model could explain task interactions by presuming that the requirement of nonword pronunciation results in a bias toward the phonological route. In that this route is presumed to be slower than the visual route, it would be predicted that latencies would therefore be slower in the words-plus-nonwords than in the words-only condition. This was the case. However, a further prediction of this view would be enhanced effects of regularity in the words-plus-nonwords condition. In fact, the opposite effect was obtained.

\section{GENERAL DISCUSSION}

\section{One Route or Two?}

An important aspect of Glushko's (1979) activation and synthesis model is the proposal that during the course of identifying a word, the lexical entries for other words possessing similar features are also activated. The fact that consistency effects were evident in both the lexical decision and the naming tasks suggests that activated inconsistent information affects a general word identification mechanism rather than simply the process involved in synthesizing a pronunciation. With this modification, the data do support the activation notion.

Glushko (1979) goes further, however, and suggests that if this activation concept is accepted, there is no need to presume that there is a second phonological route relying on GPC rules. The regularity effect and task interactions evident in the present data imply that Glushko's decision to discard the second route of the dual-access model may be premature.

Glushko's (1979) rejection of the second route is implicit rather than explicit in his discussion. The basis of the rejection is mainly parsimony since, he claims, "there is no unambiguous evidence for the use of orthographic rules as they are being proposed" (p. 686). However, as has been discussed, Glushko's use of a nonfactorial design did not allow him to evaluate whether there were effects of regularity as well as consistency.

Bauer and Stanovich (1980) specifically addressed themselves to a distinction between the activation and synthesis and the dual-access models. The logic of their test was that, according to the dual-access model, regularity effects in the lexical decision task will be enhanced if the visual route is differentially disrupted relative to the phonological route. This is because irregular words can only be accessed on the basis of their visual characteristics, whereas regular words can still achieve phonological access when the visual route is disrupted. That is, there should be an interaction between degradation and the effect of regularity.

Bauer and Stanovich (1980) tested this hypothesis using two methods of degradation and, because they failed to find the interactions predicted by the dualaccess model, concluded that "the obtained results are incompatible with the traditional dual-process models of lexical access ... and are fully compatible with Glushko's model" (p. 424). In that this conclusion relies completely on the assumption that the degradation manipulations differentially disrupted the visual route relative to the phonological route, it can be strongly disputed.

In one condition (Bauer \& Stanovich, 1980, Experiment 4), this differential disruption was claimed to be achieved by blurring the characters. To claim that this will affect visual and not phonological processing totally ignores the fact that in order for the graphemes of a word to be converted into phonemes, a featural representation of these graphemes must be available. Degradation will obviously affect the formation of this featural representation and therefore disrupt both visual and phonological routes.

Bauer and Stanovich's (1980, Experiment 3) second manipulation involved presenting cAsE aLtErNaTeD stimuli. Although it is more plausible that such a manipulation would differentially disrupt the visual route, this view relies on the assumption that the visual route is mediated by supraletter features and that the phonological route is not. The majority of evidence is not in accord with this assumption. Case alternation has consistently been found to have additive, rather than interactive, effects with memory access stages of word recognition (e.g., McClelland, 1976), suggesting that its effects are at the encoding stage, in which abstract codes for the individual letters of the stimulus are formed (e.g., Allport, 1979). Thus again, case alternation is likely to be equally disruptive for the visual and phonological routes.

It is therefore argued that Bauer and Stanovich's (1980) failures to find interactions between regularity and degradation do not provide evidence against the dual-access model. In the absence of any independent evidence against the two-route model, the present data suggest that the two routes that are the essence of the dual-access conception need to be maintained in order to explain the regularity effects observed in Experiment 2A and the apparent differences resulting from differential reliance on phonological information. However, the present version of the dual-access model needs to be modified if it is to accommodate the consistency effects observed in both the naming and lexical decision data. The easiest way to do this is simply to assume that the visual route of the dual-access model operates in much the way described by Glushko (1979). Then, whenever responses are based on visual lexical access, consistency effects will be observed. whereas if access relies on 
phonological mediation, effects of regularity will predominate. If it is further assumed that the two routes are weighted, then it is possible to accommodate both consistency effects and variability in the effects of regularity and consistency, according to the demands of the task.

However, acceptance of this modified dual-access model leads to a highly counterintuitive interpretation of the present word-naming data. In that regularity effects are observed when only words must be named, but not when both words and nonwords are included, it would be necessary to assume that subjects are biased toward the phonological route when they must read only words and toward the visual route when they must pronounce nonwords as well. This interpretation is contrary to the predictions of the dual-access model. When only words must be named (Experiment $2 \mathrm{~A}$ ), subjects can obtain all pronunciations from the lexicon and, if visual access is faster, they should therefore be biased toward the visual route. It is when nonwords must also be pronounced (Experiment $2 \mathrm{~B}$ ) that a bias toward the phonological route (and the consequent word regularity effects) would be expected.

If one were to accept the logic of the dual-access model and assume that naming of words only is accomplished by the visual route, then the regularity effects observed in Experiment 2A would have to be attributed to postlexical processes involved in converting the phonemic code retrieved from the lexicon into an articulatory program. But this interpretation raises the question of why no such phoneme-to-articulatory effects are evident in Experiment 2B when both words and nonwords must be pronounced.

The present data therefore cause problems for both the one-route and the two-route models. The consistency effects observed in all four experiments support the activation concept; but the emergence of regularity effects when only words must be named and the differences in performance resulting from changes in the nonword environment suggest that a second phonological route is available.

\section{Interactive Activation Model}

It should be made clear that the problems for the activation and synthesis model do not arise from the apparent strategic variability per se, but rather from the fact that this variation in strategy appears to reflect the existence of a phonological route. One-route models like Glushko's (1979) can accommodate some strategy variation, as is made clear by McClelland and Rumelhart's (1981) interactive activation model. This model can be regarded as a more detailed specification of the activation procedure described by Glushko and, in fact, the authors acknowledge that the treatment of pseudoword processing was inspired by Glushko. It therefore seems appropriate to consider whether this more tightly formulated activation model can deal with the data without assum- ing a phonological route to the lexicon. The model assumes that letters and words are represented in memory by logogen-like detectors called nodes, and that there are both excitatory and inhibitory connections between nodes. The model is interactive in that activation can travel both up (letter to word) and down (word to letter) the system, as well as between nodes at the same level. Simulations of the model have been directed at the forced-choice letter-detection task, for which the model is very successful at reproducing both the familiarity effects that characterize this paradigm (e.g., Reicher, 1969) and the dependency of these effects on the nature of the mask used (e.g., Johnston \& McClelland, 1973).

In order to deal with the lexical decision task, the interactive activation model would have to be extended to a description of the way in which the pattern of activity within the word level nodes could be used to make word/nonword classifications. There are plausible ways in which this could be achieved: Subjects could adopt a decision rule by which if one node was activated discriminably more strongly than others, a "word" response would be made, and if the pattern of activity did not clearly define a single detector as the target, the subject would assume that the stimulus was a pseudoword. Such a decision rule would almost certainly explain the facilitated performance observed in the presence of illegal rather than legal nonwords (Shulman et al., 1978). However, to explain the fact that performance is both faster and more accurate when some nonwords are pseudohomophones (Experiment 1A), the model would have to assume that subjects adopt different readout times, depending on the nonword environment. Specifically, it would have to be assumed that subjects analyze the pattern of activity and make a decision earlier in processing when the nonwords are pseudohomophones than when they are not. Further, the model would have to explain the paradoxical finding that this quicker response was also more accurate. It is possible to envisage a situation in which the slow activation of low frequency neighbors of the target word would result in a target node being more discriminable against the overall pattern of activation early in processing than it would be if all nodes were allowed to reach asymptote. McClelland and Rumelhart (1981) do assume that "the subject learns through experience in the practice phase of the experiment to read out the results of processing at a time that allows the subjects to optimize performance" (p. 382), so that if subjects "decided" to readout earlier in Experiment 1A than in Experiment 1B, the observed differences in latency and accuracy could feasibly occur.

But why should different readout times be adopted in Experiments 1A and 1B except because in Experiment $1 \mathrm{~A}$ the presence of pseudohomophones causes subjects to adopt an early readout time (a fast deadline) in order to avoid the influence of phonological information? Similarly, why should naming only words as opposed to 
words and nonwords result in faster latencies and effects of regularity for low frequency words, unless there is some process relying on the correspondence between letters and phonemes that allows fast pronunciations but is sensitive to irregularity at the grapheme-phoneme level?

Phonological influences can be accommodated within the complete interactive activation model, and McClelland and Rumelhart (1981) only excluded phonologicalvisual interactions from their attempted simulations of letter-detection performance to "keep the model within bounds" (p. 404), although they found it noteworthy that such interactions were not necessary to simulate letter-detection performance. But, once we are forced to assume that the letter-phoneme and phoneme-word interactions are necessary to account for the present data, we are back to a two-route model, and the interactive activation model becomes an amalgamation of the dual-access and the activation and synthesis models, rather than a specification of a one-route framework.

\section{Dual Access vs. Interactive Activation}

If it is accepted that the present results cannot be explained without assuming that phonological information does play a role in word identification, then either the interactive activation model or a modified dual-access model could provide an appropriate framework. The major problem for either view results from the fact that pronunciation can apparently be achieved through two different mechanisms, one of which is sensitive to both regularity and consistency (Experiment 2A) and one of which is sensitive only to consistency (Experiment 2B)

The traditional dual-access model explicitly assumes different pronunciation mechanisms: one relying on lexical access and one resulting from the application of GPC rules. However, as has been discussed, regularity effects are assumed to result from the GPC procedure, and the fact that such effects were observed when only words were pronounced, and not when nonwords were included, is in direct contradiction to the logic of this model. It would be possible to attribute the observed effects of regularity to postlexical conversion from a phonemic to an articulatory code, but this raises the question of why the same effects are not evident when nonwords as well as words must be named. Moreover, although the slower naming latencies observed in the words-plus-nonwords condition have previously been taken as evidence that such a task relies on the slower phonological route (Fredericksen \& Kroll, 1976), the fact that Experiment $2 B$ showed effects of consistency but not regularity is contrary to the assumption that this slower route involves the application of GPC rules. In short, if the dual-access model were modified so as to accommodate consistency effects and to cope with the fact that regularity effects are evident when a pronunciation would logically be derivable from the lexicon, it would be so remote from the traditional model as to be unrecognizable.

McClelland and Rumelhart's (1981) interactive activation model seems to lend itself to an account of consis- tency effects, although a test of this requires a specification of the way in which lexical classifications are made. This model also seems capable of providing a plausible account of the different mechanisms contributing to a pronunciation. Within this framework, pronunciations could presumably be derived either from letter-phoneme interactions, in which case they would be affected by regularity, or by synthesizing the pronunciations derived from word level nodes in the manner described by Glushko (1979). One could then assume that word level processes dominated in Experiment 2B, perhaps because the presence of nonwords somehow induces subjects to make lexical decisions, but that letter-phoneme derived pronunciations were faster in Experiment $2 \mathrm{~A}$, at least for low frequency words. The model would still have to explain why the regularity effects arising when pronunciations are derived from letter-phoneme interactions are reflected in latency rather than errors. Some sort of error-checking mechanism relying on phoneme-word interactions would have this potential. It would also be necessary to consider whether there is any functional difference between the assumption of interaction between letter and phoneme nodes and traditional GPC rules.

In general, however, the interactive activation model seems capable of explaining the present data without modification, but formal simulations would be necessary to test this assertion. Moreover, in contrast with the commonly held view that interactive models are "black boxes" that can "explain" anything (e.g., Calfee, 1977), the detailed specification of this model suggests that it is more falsifiable than the dual-access model, which, like all race models, can "proliferate the number of memories consulted" or "invent a new processing avenue for each experimental factor" (Henderson, 1977, p. 70).

\section{REFERENCE NOTE}

1. Share, D. From the printed word to meaning: A developmental study. Unpublished honors thesis, University of New South Wales, 1979.

\section{REFERENCES}

Alt.PORT, A. Word recognition in reading. In P. A. Kolers, M. E. Wrolstad, \& H. Bouma (Eds.), Processing of visible language (Vol. 1). New York: Plenum, 1977.

BARON, J. What we might know about orthographic rules. In S. Dornic (Ed.), Attention and performance VI. Hillsdale, N.J: Erlbaum, 1977.

BARoN, J., \& STrawson, C. Use of orthographic and wordspecific knowledge in reading words aloud. Journal of Experimental Psychology: Human Perception and Performance, 1976, 2, 386-393.

Bauen, D. W., \& Stanovich, K. E. Lexical access and the spelling-to-sound regularity effect. Memory \& Cognition, 1980, $8,424-432$.

BECKER, C. A. Allocation of attention during visual word recognition. Journal of Experimental Psychology: Human Perception and Performance, 1976, 2, 556-566.

CalfeE, R. C. Assessment of independent reading skills: Basic research and practical applications. In A. S. Reber \& D. L. 
Scarborough (Eds.), Towards a psychology of reading. Hillsdale, N.J: Erlbaum, 1977.

ColthenRt, M. Lexical access in simple reading tasks. In G. Underwood (Ed.), Strategies of information processing. London: Academic Press, 1978.

Colthenrt, M. Reading, phonological recoding, and deep dyslexia. In M. Coltheart, K. E. Patterson, \& J. C. Marshall (Eds.), Deep dyslexia. London: Routledge \& Kegan Paul, 1980.

Coltheart, M., Begner, D., Jonasgon, J. T., \& Davelaar, E. Phonological encoding in the lexical decision task. Quarterly Journal of Experimental Psychology, 1979, 31, 489-507.

Colthe art, M., Davelaar, E., Jonagson, J. T., \& Besner, D. Access to the internal lexicon. In S. Dornic (Ed.), Attention and performance VI. Hillsdale, N.J: Erlbaum, 1977.

Davelaar, E., Coltheart, M., Besner, D., \& Jonasson, J. T. Phonological recoding and lexical access. Memory \& Cognition, 1978, 6, 391-402.

Frederikgen, J. E., \& Kroll, J. F. Spelling and sound: Approaches to the internal lexicon. Journal of Experimental Psychology: Human Perception and Performance, 1976, 2, 361-379.

GLushko, R. J. The organization and activation of orthographic knowledge in reading aloud. Journal of Experimental Psy. chology: Human Perception and Performance, 1979, 5, 674691.

Gough, P. B., \& Cosxy, M. J. One second of reading again. In N. J. Castellan, D. B. Pisoni, \& G. R. Potts (Eds.), Cognitive theory (Vol. 2). Hillsdale, N.J: Erlbaum, 1977.

Henderson, L. Word recognition. In N. S. Sutherland (Ed.), Tutorial essays in psychology (Vol. 1). Brighton: University of Sussex, 1977.

Johnston, J. C., \& MCClelicand, J. L. Visual factors in word perception. Perception \& Psychophysics, 1973, 14, 365-370.

Kučera, H., \& Francis, W. Computational analysis of presentday American English. Providence, R.1: Brown University Press, 1967.

Marshald, J. C. Neuropsychological aspects of orthographic representation. In $\mathbf{R}$. J. Wales \& E. Walker (Eds.), New approaches to language mechanisms. Amsterdam: NorthHolland, 1976.

Mason, M. From print to sound in mature readers as a function of reader ability and two forms of orthographic regularity. Memory \& Cognition, 1978, 6, 568-581.
McClelland, J. L. Preliminary letter identification in the perception of words and nonwords. Journal of Experimental Psychology: Human Perception and Performance, 1976, 1, 80-91.

McClelland, J. L., \& RumelhaRT, D. E. An interactive activation model of context effects in letter perception: Part 1. An account of basic findings. Psychological Review, 1981, 5, 375-407.

McCusxer, L. X., Hillenger, M. L., \& Bias, R. G. Phonological recoding and reading. Psychological Bulletin, 1981, 89, 217-245.

MCQUade, D. V. Variable reliance on phonological information in visual word recognition. Language and Speech, 1981, 24, 99-109.

Meyen, D. E., Schyaneveldt, R. W., \& Ruddy, M. G. Functions of graphemic and phonemic codes in visual word recognition. Memory \& Cognition, 1974, 2, 309-321.

Morton, J. Interaction of information in word recognition. Psy. chological Review, 1969, 76, 165-178.

REicher, G. M. Perceptual recognition as a function of meaningfulness of stimulus material. Journal of Experimental Psy. chology, 1969, 81, 275-280.

Rubenstein, H., Lewis, S. S., \& Rubenstein, M. A. Evidence for phonemic recoding in visual word recognition. Journal of Verbal Learning and Verbal Behavior, 1971, 10, 645-657.

Seidenbera, M. S., \& TannenhaUs, M. K. Orthographic effects on rhyme monitoring. Journal of Experimental Psychology: Human Learning and Memory, 1979, 5, 546-554.

Shulman, H. G., Hornak, R., \& Sanders, E. The effects of graphemic, phonetic and semantic relationships on access to lexical structure. Memory \& Cognition, 1978, 6, 115-123.

Tannenhaus, M. K., Flanigan, H. P., \& Seidenbero, M. S. Orthographic and phonological activation in auditory and visual word recognition. Memory \& Cognition, 1980, 8, 513-520. VENEzKY, R. L. Regularity in reading and spelling. In $H$. Levin \& J. P. Williams (Eds.), Basic studies on reading. New York: Basic Books, 1970.

\section{NOTE}

1. Due to equipment problems, some of the data were unanalyzable. The error rates have therefore not been reported, but a cursory examination suggested that the error results paralleled the latency data.

Appendix

Lexical Decision Times (T) and Errors (E) and Naming Times for the Words Used in All Four Experiments

\begin{tabular}{|c|c|c|c|c|c|c|c|c|c|c|c|c|c|}
\hline \multicolumn{7}{|c|}{ Consistent } & \multicolumn{7}{|c|}{ Inconsistent } \\
\hline & \multicolumn{6}{|c|}{ Experiment } & & \multicolumn{6}{|c|}{ Experiment } \\
\hline & \multicolumn{2}{|c|}{$1 \mathrm{~A}$} & \multicolumn{2}{|c|}{ 1B } & \multirow[b]{2}{*}{$2 \mathbf{A}$} & \multirow[b]{2}{*}{ 2B } & & \multicolumn{2}{|c|}{$1 \mathrm{~A}$} & \multicolumn{2}{|c|}{ 1B } & \multirow[b]{2}{*}{$2 \mathrm{~A}$} & \multirow[b]{2}{*}{$2 B$} \\
\hline & $T$ & $\mathbf{E}$ & $\mathbf{T}$ & $\mathrm{E}$ & & & & $\mathbf{T}$ & $\mathrm{E}$ & $\mathrm{T}$ & $\mathbf{E}$ & & \\
\hline \multicolumn{14}{|c|}{ High-Frequency Regular Words } \\
\hline $\begin{array}{l}\text { PAIN } \\
\text { REAL } \\
\text { PART } \\
\text { MAIN } \\
\text { ROAD } \\
\text { GAME } \\
\text { LAND } \\
\text { HEAT } \\
\text { DESK } \\
\text { FLAT }\end{array}$ & $\begin{array}{l}578 \\
687 \\
618 \\
755 \\
571 \\
509 \\
566 \\
536 \\
608 \\
559\end{array}$ & $\begin{array}{l}1 \\
2 \\
1 \\
2 \\
1 \\
0 \\
0 \\
0 \\
2 \\
0\end{array}$ & $\begin{array}{l}539 \\
576 \\
637 \\
742 \\
616 \\
551 \\
499 \\
539 \\
601 \\
501\end{array}$ & $\begin{array}{l}0 \\
0 \\
0 \\
2 \\
0 \\
0 \\
0 \\
0 \\
0 \\
0\end{array}$ & $\begin{array}{l}543 \\
540 \\
541 \\
599 \\
531 \\
579 \\
560 \\
607 \\
580 \\
615\end{array}$ & $\begin{array}{l}599 \\
610 \\
651 \\
694 \\
577 \\
632 \\
683 \\
612 \\
681 \\
633\end{array}$ & $\begin{array}{l}\text { COST } \\
\text { FIVE } \\
\text { HOME } \\
\text { MASS } \\
\text { LOST } \\
\text { FOOD } \\
\text { NOSE } \\
\text { PAID } \\
\text { DEAR } \\
\text { SAVE }\end{array}$ & $\begin{array}{l}589 \\
564 \\
537 \\
548 \\
522 \\
568 \\
564 \\
698 \\
689 \\
494\end{array}$ & $\begin{array}{l}0 \\
0 \\
0 \\
0 \\
0 \\
0 \\
0 \\
1 \\
2 \\
1\end{array}$ & $\begin{array}{l}553 \\
583 \\
537 \\
570 \\
558 \\
624 \\
599 \\
608 \\
617 \\
553\end{array}$ & $\begin{array}{l}0 \\
0 \\
0 \\
1 \\
0 \\
0 \\
0 \\
0 \\
0 \\
0\end{array}$ & $\begin{array}{l}581 \\
622 \\
562 \\
602 \\
673 \\
657 \\
577 \\
578 \\
669 \\
579\end{array}$ & $\begin{array}{l}654 \\
675 \\
591 \\
646 \\
576 \\
594 \\
592 \\
622 \\
663 \\
597\end{array}$ \\
\hline
\end{tabular}


Consistent

\begin{tabular}{|c|c|c|c|c|c|c|c|c|c|c|c|c|c|}
\hline \multicolumn{7}{|c|}{ Consistent } & \multicolumn{7}{|c|}{ Inconsistent } \\
\hline & \multicolumn{6}{|c|}{ Experiment } & & \multicolumn{6}{|c|}{ Experiment } \\
\hline & \multicolumn{2}{|c|}{$1 \mathrm{~A}$} & \multicolumn{2}{|c|}{$1 \mathrm{~B}$} & \multirow[b]{2}{*}{$2 \mathrm{~A}$} & \multirow[b]{2}{*}{$2 \mathrm{~B}$} & & \multicolumn{2}{|c|}{$1 \mathrm{~A}$} & \multicolumn{2}{|c|}{$1 \mathbf{B}$} & \multirow[b]{2}{*}{$2 \mathrm{~A}$} & \multirow[b]{2}{*}{$2 \mathrm{~B}$} \\
\hline & $\mathrm{T}$ & $\mathrm{E}$ & $\mathrm{T}$ & $\mathrm{E}$ & & & & $\mathbf{T}$ & E & $\mathrm{T}$ & $\mathrm{E}$ & & \\
\hline \multicolumn{14}{|c|}{ High-Frequency Irregular Words } \\
\hline BOOK & 568 & 0 & 636 & 0 & 584 & 587 & LOVE & 617 & 2 & 510 & 0 & 577 & 644 \\
\hline PAST & 592 & 0 & 563 & 0 & 546 & 613 & WORD & 633 & 2 & 509 & 1 & 528 & 644 \\
\hline TOLD & 566 & 0 & 634 & 0 & 550 & 591 & HEAD & 564 & 0 & 537 & 0 & 594 & 651 \\
\hline BALL & 582 & 0 & 544 & 0 & 587 & 601 & MOVE & 638 & 0 & 573 & 0 & 571 & 617 \\
\hline COLD & 622 & 0 & 569 & 0 & 594 & 626 & DEAD & 602 & 0 & 612 & 0 & 596 & 713 \\
\hline FALL & 547 & 0 & 572 & 0 & 565 & 631 & LIVE & 547 & 1 & 557 & 0 & 633 & 663 \\
\hline SLOW & 580 & 0 & 570 & 0 & 551 & 682 & LOSE & 728 & 0 & 804 & 1 & 597 & 653 \\
\hline HOLD & 561 & 1 & 606 & 0 & 523 & 647 & PASS & 584 & 0 & 665 & 0 & 523 & 621 \\
\hline FAST & 567 & 0 & 592 & 0 & 590 & 615 & FOOT & 467 & 0 & 614 & 0 & 586 & 613 \\
\hline PATH & 623 & 0 & 531 & 0 & 598 & 657 & POST & 553 & 1 & 611 & 1 & 592 & 600 \\
\hline \multicolumn{14}{|c|}{ Low-Frequency Regular Words } \\
\hline FLAG & 560 & 0 & 557 & 0 & 589 & 632 & BOOT & 658 & 0 & 503 & 0 & 539 & 632 \\
\hline JUNK & 754 & 1 & 722 & 0 & 564 & 595 & DASH & 620 & 1 & 783 & 1 & 592 & 703 \\
\hline GOAT & 576 & 1 & 652 & 0 & 640 & 692 & CAVE & 627 & 1 & 606 & 0 & 573 & 655 \\
\hline DISH & 528 & 2 & 543 & 1 & 571 & 601 & BROW & 744 & 4 & 813 & 0 & 654 & 744 \\
\hline HEEL & 741 & 4 & 612 & 0 & 535 & 628 & DOLL & 621 & 2 & 732 & 1 & 488 & 642 \\
\hline DOOM & 595 & 2 & 711 & 1 & 590 & 651 & HIVE & 670 & 0 & 779 & 0 & 510 & 658 \\
\hline CART & 611 & 2 & 793 & 0 & 534 & 681 & HOOT & 664 & 2 & 813 & 6 & 645 & 681 \\
\hline FLOP & 706 & 1 & 717 & 0 & 643 & 660 & JOWL* & 820 & $1 \overline{5}$ & 908 & 13 & 691 & 772 \\
\hline SOFT & 569 & 1 & 571 & 0 & 587 & 619 & LASS & 665 & 0 & 767 & 1 & 588 & 647 \\
\hline SAIL & 561 & 0 & 572 & 0 & 542 & 641 & NULL & 770 & 1 & 796 & 1 & 568 & 745 \\
\hline \multicolumn{14}{|c|}{ Low-Frequency Irregular Words } \\
\hline MILD & 587 & 0 & 578 & 1 & 568 & 582 & PINT & 661 & 2 & 668 & 0 & 683 & 775 \\
\hline HIND & 612 & 1 & 861 & 2 & 622 & 712 & HOOD & 632 & 0 & 606 & 0 & 564 & 628 \\
\hline FOLD & 641 & 0 & 606 & 0 & 603 & 639 & COMB & 694 & 0 & 667 & 0 & 620 & 756 \\
\hline CALF & 624 & 1 & 558 & 0 & 678 & 675 & TOMB & 633 & 4 & 737 & 1 & 675 & 775 \\
\hline HALT & 617 & 0 & 621 & 0 & 582 & 639 & WOOL & 589 & 2 & 686 & 0 & 578 & 650 \\
\hline BIND & 609 & 0 & 685 & 1 & 604 & 599 & SOOT* & 840 & 3 & 912 & 6 & 654 & 666 \\
\hline MASK & 573 & 1 & 571 & 0 & 556 & 581 & FOUR & 736 & 0 & 721 & 2 & 640 & 643 \\
\hline HOOK & 668 & 2 & 577 & 0 & 552 & 632 & CROW & 717 & 2 & 689 & 0 & 694 & 634 \\
\hline MAST & 598 & 1 & 692 & 0 & 605 & 691 & RIND* & 759 & 3 & 1067 & 7 & 603 & 626 \\
\hline MALT & 606 & 2 & 717 & 0 & 603 & 622 & PUSH & 511 & 0 & 611 & 1 & 535 & 558 \\
\hline
\end{tabular}

*Excluded from analysis because of excessive error rates.

(Received for publication December 22, 1981;

revision accepted July 28,1982 .) 